RECEBIDO EM 23/05/2014. ACEITO EM 09/11/2014.

\title{
Sistemática para balanceamento de célula de manufatura integrando abordagens determinística e estocástica: estudo de caso em uma empresa do ramo automotivo
}

\author{
Cristina da Silva Torres \\ Universidade Federal do Rio Grande do Sul - UFRGS \\ cristinastorres@gmail.com
}

Fernando de Oliveira Lemos

Pontifícia Universidade Católica do Rio Grande do Sul (PUCRS)

fernando.lemos@pucrs.br

\section{RESUMO}

Um dimensionamento adequado dos recursos produtivos é essencial para a competitividade das empresas frente ao mercado globalizado. Uma das formas para dimensionamento dos recursos é o balanceamento de célula de manufatura. Existem duas formas principais para realização de balanceamento de célula de manufatura: análise determinística e estocástica. Este artigo propõe uma sistemática para balanceamento de célula de manufatura integrando abordagens determinística e estocástica, a fim de avaliar a utilização dos recursos em uma indústria do ramo automotivo. A sistemática proposta está estruturada em três fases, e demonstra a contribuição resultante da integração entre o balanceamento determinístico e a simulação computacional. A partir da sistemática proposta reduziu-se em $25 \%$ a necessidade de recursos e obteve-se uma melhoria de até $76 \%$ na utilização dos recursos.

Palavras-chave: Balanceamento de Células; Manufatura Celular; Simulação Computacional.

\begin{abstract}
A correct sizing of productive resources is essential for the competitiveness of companies across the global market. One way for resources sizing is by doing cell balancing. There are two main ways to perform cell balancing: deterministic and stochastic analysis. This article proposes a systematic to balancing manufacturing cell integrating deterministic and stochastic approaches in order to evaluate the use of resources in a factory of the automotive industry. The systematic proposed is structured in three phases, and demonstrates the contribution resulting from the integration of the deterministic balancing and computational simulation. From the systematic proposed had as results a reduction of $25 \%$ on the need of resources and an improvement of $76 \%$ in the utilization of resources.
\end{abstract}

Keywords: Cell Balancing; Cellular Manufacturing; Computational Simulation. 


\section{Introdução}

No contexto do mercado atual, as organizações dependem da racionalização dos recursos internos para aumentar o seu potencial competitivo. Esta situação ocorre no ramo automotivo, o qual tem sido marcado pela introdução de novos conceitos de gestão e de princípios de manufatura enxuta (ANTUNES, 1998).

A utilização da manufatura celular permite que as empresas coloquem em prática os princípios da manufatura enxuta (SHINGO, 1996). Para a obtenção de melhores resultados com a manufatura celular, faz-se necessário o balanceamento dos recursos utilizados na célula de manufatura.

O objetivo do balanceamento é atingir a homogeneidade de carga de trabalho entre os operadores, para que o tempo de ciclo em cada posto de trabalho não ultrapasse o takt-time de produção (MASSOD, 2006). Existem duas formas principais para realização de balanceamento de célula de manufatura: análise determinística e estocástica.

O tema deste estudo é o balanceamento de célula de manufatura utilizando análises determinística e estocástica. Ao realizar o balanceamento, com base em dados estocásticos, é possível utilizar softwares de modelagem e simulação computacional, os quais possibilitam a visão sistêmica do sistema produtivo e são capazes de demonstrar o comportamento da célula de manufatura por meio de recursos de animação e de análises estatísticas (CARSON, 2004).

O objetivo geral deste trabalho é propor uma sistemática para balanceamento de célula de manufatura, integrando as abordagens determinística e estocástica. Como objetivos específicos, compreendem-se três questões: (i) analisar as sistemáticas de balanceamento utilizadas; (ii) simular o balanceamento realizado pela abordagem determinística utilizando a simulação computacional; e (iii) analisar e comparar os resultados obtidos nas abordagens determinística e estocástica. O estudo proposto avaliou os impactos que a sistemática de balanceamento produz na utilização dos recursos de uma célula. Neste estudo não foram analisados os impactos econômicos resultantes do balanceamento, somente os impactos operacionais no processo.

Como justificativa, optou-se pela utilização da modelagem e simulação computacional devido à capacidade que esta técnica computacional tem de simular sistemas produtivos com dados estocásticos (CARSON, 2004). Além disso, a empresa em que o estudo foi realizado possui uma sistemática para balanceamento determinístico, baseada na técnica de balanceamento Yamazumi, a qual não possibilita a análise das variáveis estocásticas (GOMES et al., 2008).

O presente estudo está subdividido em cinco seções: uma introdução que aborda o tema, objetivos gerais e específicos, justificativas e delimitações do estudo; uma seção de referencial teórico; uma seção na qual é apresentada a sistemática proposta; uma seção de aplicação e análise dos resultados da sistemática proposta; e uma última seção com considerações finais e sugestões para estudos futuros.

\section{Referencial teórico}

Nesta seção são apresentados os conceitos sobre manufatura celular, balanceamento e simulação computacional, com objetivo de embasar tecnicamente a aplicação prática realizada.

\subsection{Manufatura celular}

A manufatura celular é uma forma de organização do trabalho com o objetivo de melhorar a eficiência e produtividade, com trabalhadores multifuncionais, que deslocam-se de forma a atender todas as operações do processo, e com um layout de produção organizado para agrupar processos semelhantes em operações ou processos dedicados a uma família de produtos, com características similares (PRASAD; ARAVINTHAN, 2011; ANGRA et. al., 2007). 
A partir da utilização do conceito de manufatura celular, é possível (MARODIN; SAURIN, 2007; BARROSO; TUBINO, 2004; MILTENBURG, 2001): reduzir as distâncias percorridas; reduzir os estoques intermediários; reduzir espaço físico; reduzir tempos de fabricação e lead time de produção; melhorar os aspectos biomecânicos relacionados às atividades a serem executadas pelo operador; e aumentar a quantidade e a qualidade das unidades produzidas.

O balanceamento da célula de manufatura é um dos pontos críticos para a implantação da manufatura celular, de forma a evitar perdas por má utilização da mão de obra e recursos operacionais (OLORUNNIWO; UDO, 2002).

\subsection{Balanceamento de célula de manufatura}

Existem diversas técnicas e sistemáticas para balanceamento de uma célula de manufatura. A Figura 1 apresenta algumas sistemáticas, em ordem cronológica, utilizadas em trabalhos científicos, para fins de balanceamento, bem como sua abordagem (determinística ou estocástica) e objetivos.

Figura 1 - Sistemáticas de balanceamento utilizadas em trabalhos científicos

\begin{tabular}{|c|c|c|c|}
\hline Fonte & Sistemática & Fundamentação & Objetivo \\
\hline $\begin{array}{l}\text { Lehman } \\
(1969)\end{array}$ & Programação linear & Determinística & $\begin{array}{l}\text { Minimizar o custo total decorrente } \\
\text { do desbalanceamento. }\end{array}$ \\
\hline $\begin{array}{l}\text { Erel e Gokcen } \\
\qquad(1999)\end{array}$ & $\begin{array}{l}\text { Algoritmo da Rota mais } \\
\text { Curta }\end{array}$ & Determinística & $\begin{array}{c}\text { Encontrar a solução ótima do } \\
\text { problema de balanceamento de } \\
\text { linhas de } \\
\text { modelo único. }\end{array}$ \\
\hline $\begin{array}{l}\text { Khan e Day } \\
\text { (2002) }\end{array}$ & $\begin{array}{l}\text { Knowledge Based Design } \\
\text { Methodology (KBDM) }\end{array}$ & Estocástica & $\begin{array}{l}\text { Encontrar a solução do } \\
\text { balanceamento baseado no } \\
\text { conhecimento obtido. }\end{array}$ \\
\hline $\begin{array}{l}\text { Gehrardt e } \\
\text { Fogliatto } \\
(2004)\end{array}$ & Diagrama de precedência & Determinística & $\begin{array}{l}\text { Apresentar possibilidades na } \\
\text { sequência das atividades. }\end{array}$ \\
\hline $\begin{array}{l}\text { Lu e Wong } \\
\text { (2005) }\end{array}$ & $\begin{array}{l}\text { Simulação Computacional } \\
\text { Software ProModel }\end{array}$ & Estocástica & $\begin{array}{l}\text { Auxiliar a realização de } \\
\text { balanceamento com } \\
\text { fundamentação estocástica }\end{array}$ \\
\hline Farnes (2006) & Peso Posicional & Determinística & $\begin{array}{l}\text { Atribuir elementos às estações na } \\
\text { ordem decrescente dos valores de } \\
\text { Peso Posicional. }\end{array}$ \\
\hline $\begin{array}{l}\text { Gomes et. al. } \\
\text { (2008) } \\
\text { Whitfield } \\
(2001)\end{array}$ & $\begin{array}{c}\text { GBM (Gráfico } \\
\text { Balanceamento de } \\
\text { Máquinas)/ GBO(Gráfico } \\
\text { Balanceamento de } \\
\text { Operadores)/ Yamazumi }\end{array}$ & Determinística & $\begin{array}{l}\text { Alocação de tarefas entre } \\
\text { operadores, de forma a chegar o } \\
\text { mais próximo da linha do takt- } \\
\text { time. }\end{array}$ \\
\hline $\begin{array}{l}\text { Fernandes et. } \\
\text { al. }(2008) \\
\text { Askin e Zhou } \\
\quad(1997)\end{array}$ & Programação Inteira & Determinística & $\begin{array}{l}\text { Minimizar o excesso de trabalho } \\
\text { existente nas estações. }\end{array}$ \\
\hline $\begin{array}{l}\text { SILVA et. al. } \\
\quad(2010)\end{array}$ & $\begin{array}{l}\text { Simulação Computacional } \\
\text { Software Arena }\end{array}$ & Estocástica & $\begin{array}{l}\text { Auxiliar a realização de } \\
\text { balanceamento com } \\
\text { fundamentação estocástica }\end{array}$ \\
\hline $\begin{array}{l}\text { OLIVEIRA } \\
\text { et. al. }(2011)\end{array}$ & $\begin{array}{l}\text { Metodologia MTM } \\
\text { (Methods-Time } \\
\text { Measurement) }\end{array}$ & Determinística & $\begin{array}{l}\text { Auxiliar a evidenciar os pontos } \\
\text { fortes e fracos do processo } \\
\text { produtivo, nas atividades que } \\
\text { sofrem influência do homem. }\end{array}$ \\
\hline
\end{tabular}

Fonte: Elaborada pela autora

O presente estudo abordará a sistemática Yamazumi. O Yamazumi é uma ferramenta criada na Toyota para determinar quais tarefas devem ser executadas por cada operador, 
nivelando-as o mais próximo possível do takt-time. As tarefas são classificadas em atividades que agregam e não agregam valor. A linha do takt-time é referência para a distribuição das tarefas e de possíveis balanceamentos (GOMES et al., 2008).

$\mathrm{O}$ balanceamento tradicional busca o nivelamento dos tempos de ciclo de cada operador, a fim de uniformizar a carga de trabalho, não ultrapassando o takt-time (GUINATO, 2000). O número mínimo teórico de estações de trabalho resulta da divisão da soma dos tempos de duração das atividades individuais pelo takt-time (STEVENSON, 2011). $\mathrm{O}$ takt-time representa o ritmo de produção para atendimento da demanda, considerando as restrições de capacidade da célula de manufatura. Para calcular o takt-time, calcula-se a razão entre o tempo disponível para produção e a demanda (SLACK et al., 2006).

Após realizar o cálculo do número de estações de trabalho, devem-se transferir elementos de trabalho entre operadores, até que fique balanceada a carga de trabalho entre os operadores. Desta forma pode-se diminuir a quantidade de recursos, e como consequência ter um ganho em produtividade (BLACK, 2001).

Para definir se há defasagem no balanceamento deve-se calcular o percentual de tempo ocioso da linha. Para calcular este percentual divide-se o tempo ocioso por ciclo pelo valor obtido na multiplicação do número de estações de trabalho pelo takt-time (STEVENSON, 2011).

Para verificação dos resultados obtidos com o balanceamento determinístico de células de manufatura pode-se utilizar a simulação computacional.

\subsection{Simulação computacional}

A simulação computacional permite análises de diversos cenários, com o menor gasto possível, e é uma ferramenta na tomada de decisão. Law e Kelton (2000) definem simulação como o ato de criar um sistema real, modelado em computador, com o intuito de avaliar seu desempenho.

Os modelos de simulação podem ser classificados como (BANKS, 2000): (i) Modelos de simulação estáticos ou dinâmicos; (ii) Modelos de simulação determinísticos ou estocásticos; e (iii) Modelos de simulação discretos ou contínuos. Detalhes sobre cada classificação podem ser obtidas em Banks (2000).

Ao realizar balanceamentos de célula de manufatura, utilizando sistemáticas de base determinísticas, não é possível verificar o real comportamento da célula, visto que não se consegue descrever parâmetros dinâmicos de modelagem para descrição do sistema produtivo. Entretanto, ao utilizar a simulação computacional como ferramenta de apoio para o balanceamento de célula de manufatura, é possível utilizar dados estocásticos e representar as aleatoriedades (MENDES et al., 2005).

Para modelar e simular um sistema de manufatura utiliza-se uma sistemática com as seguintes etapas (LAW; KELTON, 2000): (i) formulação do modelo conceitual; (ii) coleta de dados e (iii) programação do modelo. A estrutura do sistema, incluindo as interações entre os componentes, o levantamento das hipóteses sobre as variações desses componentes e os parâmetros e variáveis incluídas no sistema, permitem a formulação do Modelo Conceitual. A Coleta de Dados está vinculada à Formulação do Modelo, uma vez que será a partir das informações obtidas que o mesmo será desenvolvido. Os dados coletados devem ser altamente confiáveis, para assegurarem credibilidade ao Modelo e ao processo de tomada de decisão (LAW; KELTON, 2000).

\section{Sistemática proposta}

A sistemática proposta para integração de modelos de balanceamento está estruturada em três fases, apresentadas na Figura 2.

$\mathrm{Na}$ primeira fase realiza-se um balanceamento puramente determinístico. Na Fase 2 integra-se o balanceamento determinístico com análises estocásticas, por meio da utilização da simulação computacional. Na terceira, e última fase, os resultados são analisados e propõe- 
se melhorias no processo de balanceamento estudado. Cada fase é detalhada na seção 4, na qual é discriminada a aplicação da sistemática proposta.

Figura 2 - Sistemática proposta

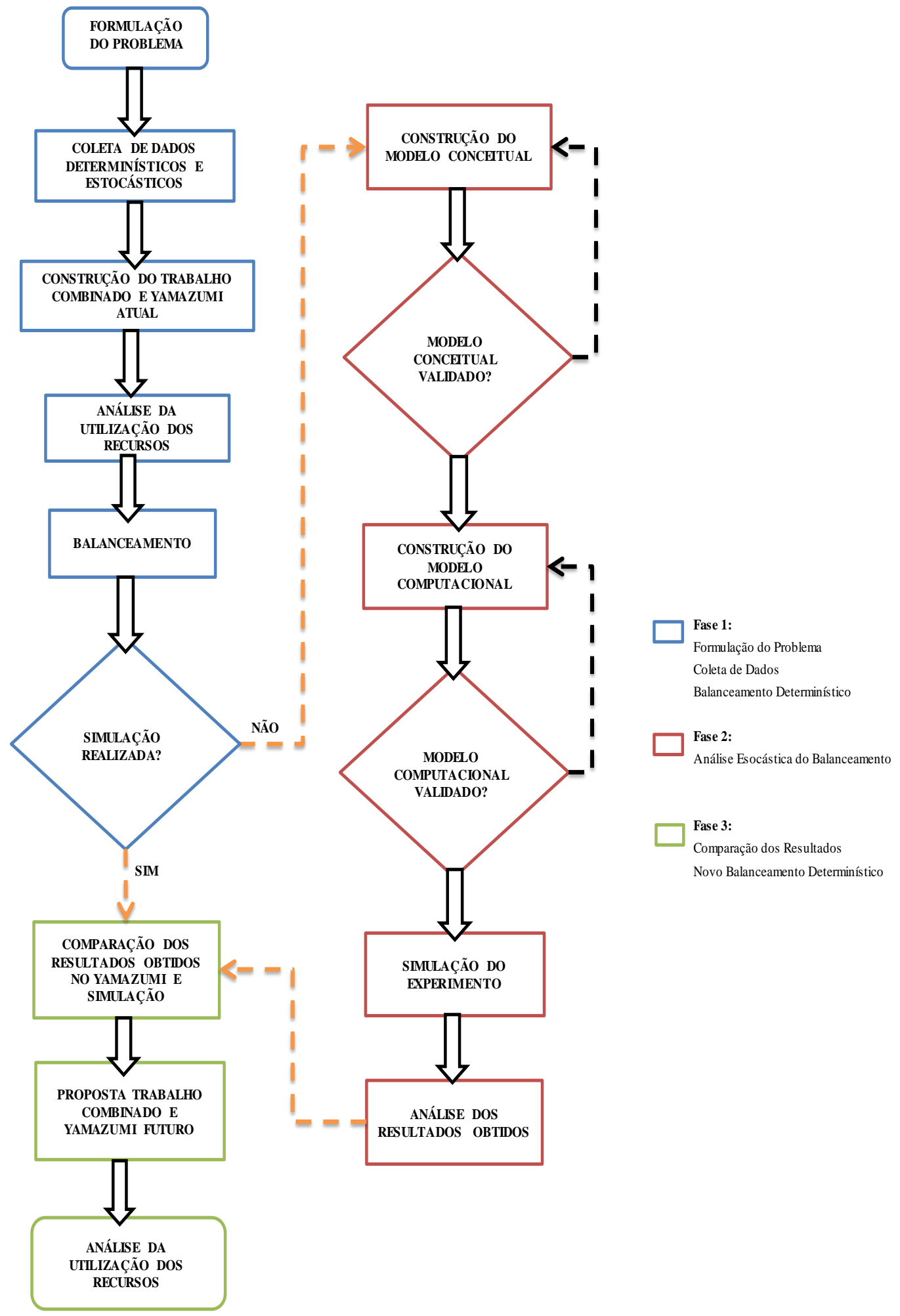

Fonte: Adaptado de Law e Kelton (2000) e Whitfield (2001) 
Este estudo foi realizado em uma empresa multinacional do ramo automotivo. Mais especificamente, em planta do Rio Grande do Sul, onde estão algumas das principais operações de usinagem do grupo no país.

\subsection{Fase 1: Formulação do problema}

A Fase 1 iniciou com a realização de reuniões de Kaizen para identificação dos problemas de balanceamento de recursos em uma célula de manufatura selecionada. A partir de observações preliminares constatou-se que a célula de manufatura apresentava altos estoques intermediários e alto lead time, em consequência da falta de balanceamento da carga de trabalho dos operadores, uma vez que o tempo de pausa de alguns operadores era maior do que o de outros.

Realizou-se o Mapeamento do Fluxo de Valor e constatou-se um tempo de processamento total de 5,4 horas/peça. Entretanto, devido aos altos níveis de estoques em processo, o lead time de produção era de 13,14 dias/peça.

Com a identificação das perdas na célula de manufatura, foi definido o problema a ser resolvido. A partir da definição do problema, seguiu-se para a fase de coleta de dados.

\subsubsection{Fase 1: coleta de dados}

Após a reunião de Kaizen e formulação do problema, foi realizada a coleta de dados de tempos necessários para o balanceamento determinístico. Na abordagem determinística (Yamazumi) utiliza-se a média dos tempos; já na abordagem estocástica utiliza-se todos os tempos, a fim de analisar as variabilidades. A partir da coleta de tempos, pode-se construir o trabalho combinado das atividades, por posto de trabalho. Assim, pode-se gerar o gráfico de balanceamento Yamazumi e analisar a utilização dos recursos.

A célula de manufatura analisada produz um item utilizado no sistema de transmissão de torque de veículos pesados, como caminhões, ônibus e caminhonetes. A célula possuía oito máquinas, dispostas em layout tipo "U". Destas oito máquinas, dois tornos realizavam a operação tornear perfil, pois essa operação era uma restrição do processo e necessitava de duas máquinas em paralelo para atender ao programa de produção. Na Figura 3 está representado o arranjo produtivo, no qual os operadores estão representados por letras e as máquinas por números. 
Figura 3 - Sequenciamento das operações e distribuição dos operadores

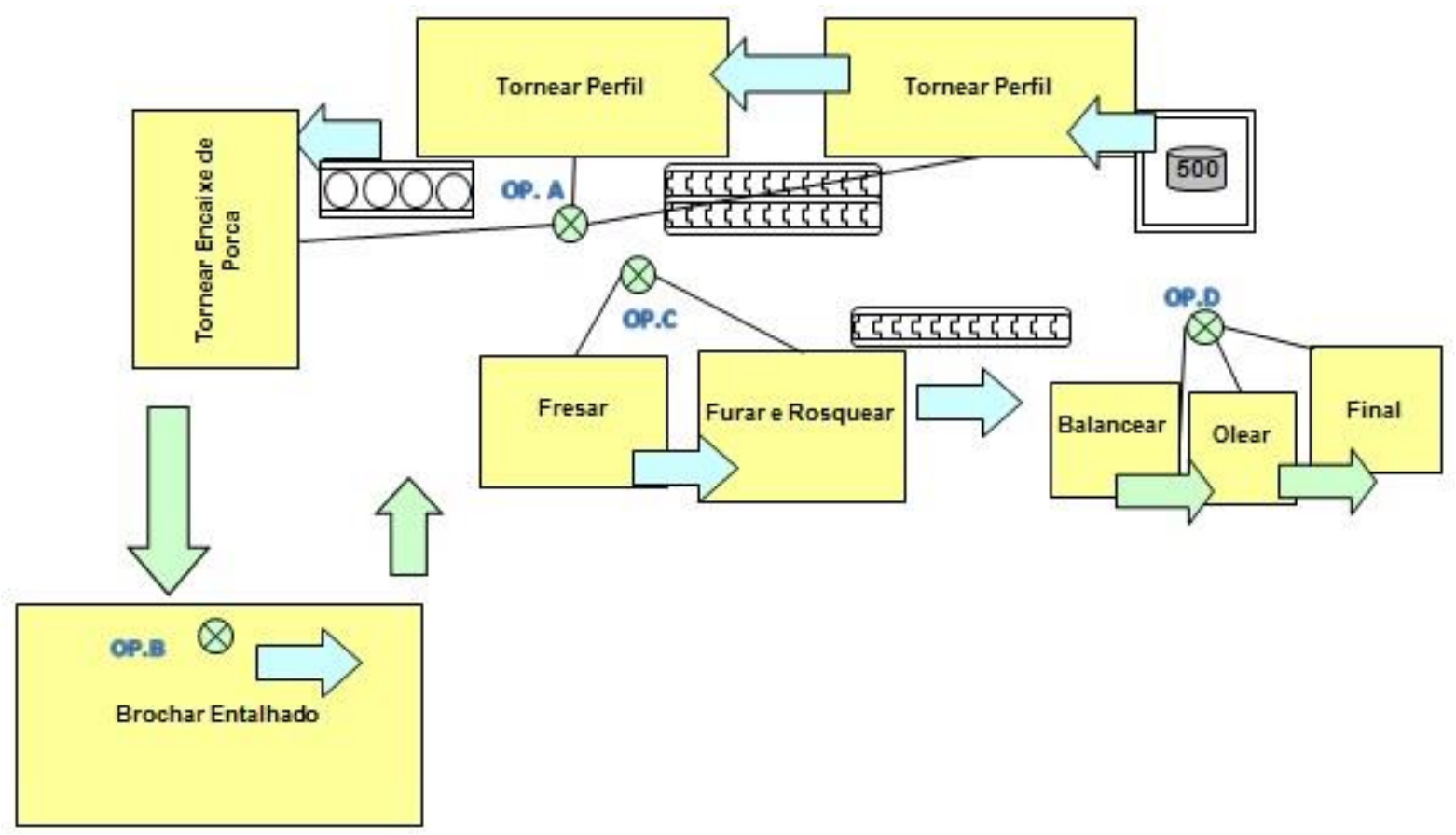

Fonte: Elaborada pela autora a partir de dados da empresa

O Operador A era responsável pelas operações de tornear perfil e tornear encaixe de porca. O Operador B realizava a operação de brochar entalhado. Esta operação ficava alocada em uma plataforma de 2 metros, e as peças chegavam e saiam em lotes de 30 peças através de um elevador. O Operador C fazia as operações de fresar e furar/rosquear. O Operador D fazia as operações de balancear, olear e empacotar as peças.

A demanda média mensal da célula de manufatura era de 13.080 peças. Consideramse 25 dias mensais para produção, a demanda diária era 523 peças. A jornada diária de trabalho é de 8 horas, em 3 turnos por dia, com uma hora de intervalo. Logo, consideram-se 21 horas disponíveis para produção por dia. A partir destes dados, foi possível calcular um tak-time de 144 segundos/peça para a célula de manufatura estudada.

Após o cálculo do takt-time, realizou-se os estudos de tempos. Analisaram-se os seguintes tempos: a carga e descarga das máquinas, deslocamentos entre operações e o tempo padrão de cada operação. O tamanho da amostra, da coleta de tempos, com grau de confiança de $95 \%(z=1,96)$, é igual a oito cronometragens de cada elemento. Para o balanceamento determinístico, utilizou-se a média dos tempos de cada atividade.

\subsubsection{Fase 1: Balanceamento determinístico}

Nesta etapa foi realizada a estruturação do trabalho combinado com a operação gargalo (operação com maior tempo de ciclo). No caso da célula de manufatura em estudo, o gargalo é o centro de usinagem, máquina para furar e rosquear, a qual é operada pelo Operador C. Com a estruturação do Trabalho Combinado, foi possível gerar o gráfico Yamazumi.

O gráfico Yamazumi permitiu a análise das atividades que agregam e não agregam valor. Utilizaram-se cores para estratificar as atividades: em verde estão as atividades que agregam valor; em vermelho, as que não agregam valor; em amarelo estão os deslocamentos; e em azul estão representadas as pausas. Na Tabela 1 são apresentados os resultados obtidos no gráfico Yamazumi. Os resultados de utilização dos operadores relata o percentual de tempo em que o operador está exercendo suas atividades, em relação ao tempo do takt-time. 
Tabela 1 - Dados obtidos no Gráfico Yamazumi

\begin{tabular}{cccccc}
\hline Operador & Utilização & Agrega Valor & Não Agrega Valor & Caminhada & Pausa \\
\hline A & $94 \%$ & 58 segundos & 52 segundos & 16 segundos & 17 segundos \\
B & $19 \%$ & 6 segundos & 13 segundos & 8 segundos & 116 segundos \\
C & $51 \%$ & 30 segundos & 32 segundos & 11 segundos & 70 segundos \\
D & $45 \%$ & 39 segundos & 16 segundos & 10 segundos & 78 segundos \\
& \multirow{2}{*}{ Total } & 133 segundos & 113 segundos & 45 segundos & 281 segundos \\
\hline
\end{tabular}

Fonte: Elaborada pela autora

O cálculo do percentual de ociosidade do balanceamento possibilitou verificar uma ocorrência de defasagem no balanceamento. A partir do cálculo do percentual de ociosidade, constatou-se que a célula de manufatura permance 48,78\% ociosa. Ao finalizar o balanceamento determinístico foi realizada a análise de dados estocásticos, utilizando como ferramenta de apoio o software de simulação computacional ProModel.

\subsection{Fase 2: Análise estocástica do balanceamento}

Com a realização do balanceamento da célula de manufatura, utilizando a técnica determinística Yamazumi, iniciou-se a Fase 2 da sistemática, que objetiva analisar o balanceamento, gerado na Fase 1, a partir de uma análise estocástica utilizando um software de modelagem e simulação computacional. A simulação computacional é utilizada como ferramenta para validação dos resultados obtidos nas análises determinísticas.

A coleta de dados da Fase 1 foi utilizada como base para a construção do modelo conceitual. A principal diferença entre as análises determinística e estocástica foi a utilização dos dados da coleta de tempos. Na Fase 1 utilizou-se a média dos tempos de cada atividade para estruturar o trabalho combinado. Entretanto, com o apoio da simulação computacional, pode-se utilizar toda a amostra de dados, e assim verificar as variabilidades do sistema produtivo.

Para a construção do modelo conceitual, foram estipuladas as seguintes considerações: (i) o modelo devia representar as mesmas atividades estipuladas no trabalho combinado; (ii) os operadores deveriam estar disponíveis $100 \%$ para realizarem as atividades; (iii) não haveria falta de matéria-prima; e (iv) não haveria retrabalho, ou seja, taxa de qualidade de $100 \%$.

Desta forma foi construído o modelo computacional, a fim de modelar e simular o estado atual da célula de manufatura. Na Figura 4 está representado o arranjo produtivo gerado no software de simulação. 
Figura 4 - Modelo Computacional

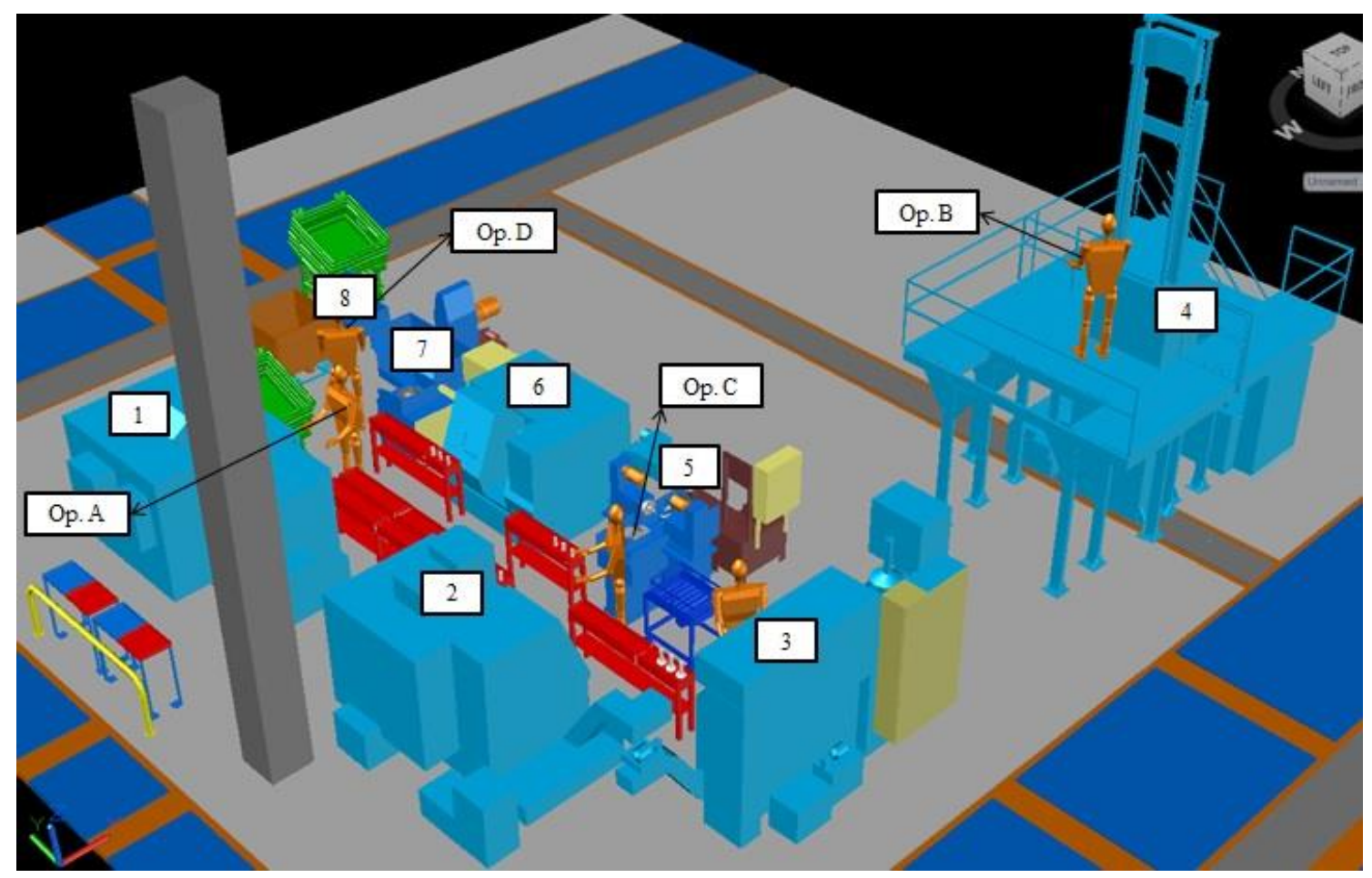

Fonte: Elaborada pela autora a partir de dados da empresa

Na Figura 5 estão descritas as operações desempenhadas pelas máquinas, bem como a distribuição dos operadores.

Figura 5 - Distribuição dos Recursos nas Operações

\begin{tabular}{ccc}
\hline Máquina & Operação & Operador \\
\hline 1 & Tornear Perfil & $\mathrm{A}$ \\
2 & Tornear Perfil & $\mathrm{A}$ \\
3 & Tornear Encaixe de Porca & $\mathrm{A}$ \\
4 & Brochar Entalhado & $\mathrm{B}$ \\
5 & Fresar & $\mathrm{C}$ \\
6 & Furar e Rosquear & $\mathrm{C}$ \\
7 & Balancear & $\mathrm{D}$ \\
8 & Olear e Empacotar & $\mathrm{D}$ \\
\hline
\end{tabular}

Fonte: Elaborada pela autora

A simulação foi realizada utilizando os mesmos dados de produção, jornada de trabalho, tarefas e tempos de operações utilizados no balanceamento determinístico (Fase 1). Considerou-se 5 horas de tempo de aquecimento e mais 21 horas (um dia de produção) para realização da simulação. Analisou-se o modelo em relação à movimentação das entidades (produto em processamento) e recursos (operadores) e verificou-se que estavam realizando o fluxo conforme o processo real.

Conforme dados coletados (seção 4.1.2), a produção diária é de 523 peças. A capacidade da célula de manufatura a $100 \%$ de eficiência é de 546 peças. O modelo computacional obteve como capacidade produtiva 618 peças. Portanto, houve uma variação de aproximadamente 11,65\%, considerada aceitável, uma vez que na simulação considerou-se 
eficiência de $100 \%$. Com a simulação, foi possível analisar o percentual de utilização dos operadores (Figura 6).

Figura 6 - Utilização dos Operadores

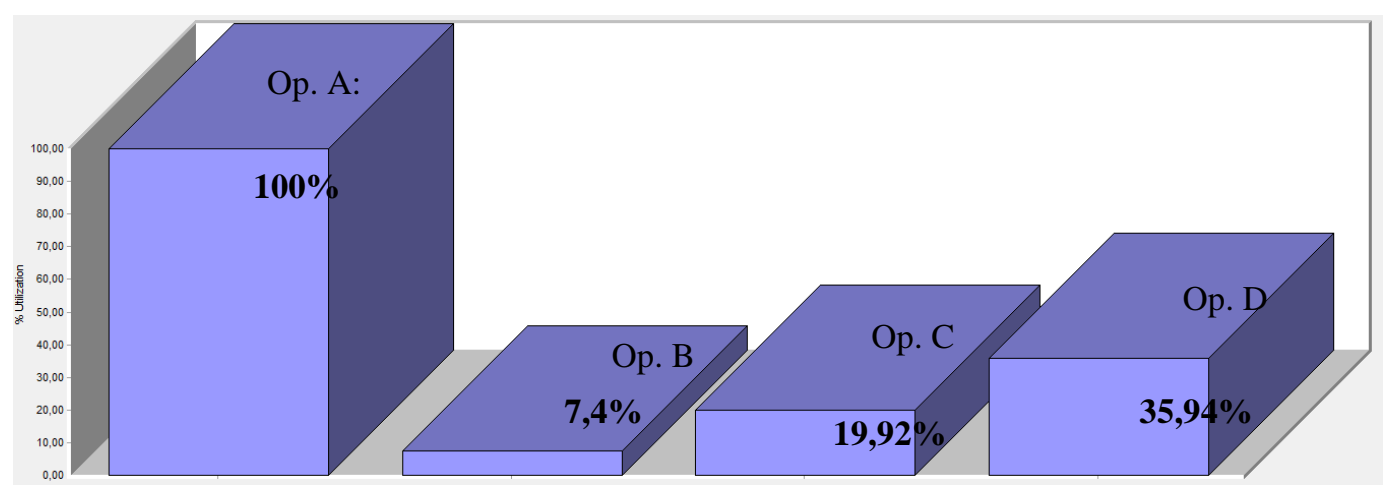

Fonte: Elaborado pela autora a partir dos resultados dos relatórios de simulação no ProModel

Para entendimento e visão sistêmica do arranjo produtivo, analisou-se a ocupação das máquinas. Para assim entender as diferenças encontradas no percentual de utilização das abordagens determinística e estocástica. Na Tabela 2 estão descritos os dados de ocupação de máquinas obtido na simulação computacional.

Tabela 2 - Dados de Ocupação das Máquinas

\begin{tabular}{ccccc}
\hline Operador & Máquina & \% Tempo em Operação & \% Tempo Ocioso & \% Tempo em Espera \\
\hline A & 1 & $68,81 \%$ & $0 \%$ & $31,19 \%$ \\
A & 2 & $46,55 \%$ & $0 \%$ & $53,45 \%$ \\
A & 3 & $36,45 \%$ & $0 \%$ & $63,55 \%$ \\
B & 4 & $27,11 \%$ & $72,89 \%$ & $0 \%$ \\
C & 5 & $48,54 \%$ & $33,10 \%$ & $10,49 \%$ \\
C & 6 & $66,63 \%$ & $27,73 \%$ & $5,64 \%$ \\
D & 7 & 67,26 & $29,72 \%$ & $3,02 \%$ \\
D & 8 & $56,4 \%$ & $32,7 \%$ & $7,48 \%$ \\
\hline
\end{tabular}

Fonte: Elaborado pela autora a partir dos resultados dos relatórios de simulação no ProModel

O percentual de tempo em operação é o tempo em que a máquina está efetivamente agregando valor ao produto, ou seja, a peça está sendo manufaturada. O percentual de tempo ocioso é o tempo em que a máquina fica sem operar, ou seja, não há peça para ser manufaturada. Já o percentual de tempo em espera é o tempo em que a máquina fica com a peça após a sua operação, mas o operador ainda não descarregou.

Analisando os dados de ocupação de máquinas, percebe-se que a máquina 4 passava $72,89 \%$ do tempo ociosa. Como consequência, as máquinas das operações seguintes também apresentavam tempos ociosos. O que acarretava em diminuição na utilização dos recursos disponíveis.

A análise de ocupação de máquinas e consequente impacto na utilização dos recursos, não podem ser realizados no balanceamento determinístico, o qual não possibilita a análise de variabilidades no processo. Utilizando os dados coletados na Fase 1 na simulação computacional, foi possível verificar o comportamento da célula de manufatura, e assim indicar melhorias a serem realizadas. 
Na Fase 3 são comparados os resultados de utilização dos recursos obtidos nos balanceamentos determinísticos e estocásticos, e são identificadas possibilidades de mudanças no balanceamento. Nesta fase propõe-se um novo balanceamento determinístico e uma análise da utilização dos recursos.

Os resultados de utilização obtidos na simulação computacional foram comparados com o balanceamento do gráfico Yamazumi. A comparação e diferenças encontradas estão apresentadas na Tabela 3 .

Tabela 3 - Comparação da Utilização dos Operadores

\begin{tabular}{cccc}
\hline Operador & Yamazumi & ProModel & Diferença \\
\hline A & $94 \%$ & $100 \%$ & $6 \%$ \\
B & $19 \%$ & $7,4 \%$ & $6,1 \%$ \\
C & $51 \%$ & $19,92 \%$ & $60,94 \%$ \\
D & $45 \%$ & $35,94 \%$ & $20,13 \%$
\end{tabular}

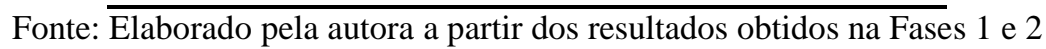

Verificou-se diferenças significativas nos valores de utilização encontrados no Yamazumi e na simulação Computacional. A principal diferença encontrada foi na utilização do Operador C, com 60,94\% de diferença nos valores encontrados. Explica-se esta diferença devido aos dados de ocupação de máquina (Tabela 2), em que a máquinas 5 e 6 , operadas pelo Operador C, apresentavam juntas $60,83 \%$ de tempo ocioso.

A diferença encontrada na utilização do Operador B, explica-se pelo fato de a máquina 4 estar localizada em uma plataforma e as peças chegarem em lotes de 30 peças, por meio de um elevador. Desta forma, o máquina 4 apresentou o maior percentual de tempo ocioso $(72,89 \%)$, o que impactou na utilização do Operador C. Devido às questões de percentual de ociosidade de máquinas e consequente utilização dos recursos, o Operador D que estava alocado nas últimas operações, também apresentou diferença nos resultados de utilização obtidos nas análises determinística e estocástica.

\subsubsection{Fase 3: Novo balanceamento determinístico}

Com as análises de comparação dos resultados obtidos, iniciou-se a etapa de novo balanceamento determinístico. Para tanto, calculou-se o número de estações de trabalho necessárias (2,41 estações). Utilizou-se a soma dos tempos manuais coletados e o resultado do cálculo do takt-time (seção 4.1.2).

Conforme o resultado de 2,41 estações, seriam necessárias 3 estações. Se a opção for trabalhar com 2 estações deve-se estudar ajustes no processo. Neste caso, estudou-se a possibilidade de colocar a operação da máquina 7 na plataforma em que se encontra a Máquina 4. A partir dos dados de utilização da Tabela 3, optou-se por agregar as atividades dos operadores B (7,4\% de utilização) e D (35,94\% de utilização), em função do operador C $(19,92 \%$ de utilização) operar a máquina gargalo da célula de manufatura. Desta forma, o operador C passaria a ser responsável pelas máquinas 5, 6 e 8 .

Na Figura 7 estão descritas as operações desempenhadas pelas máquinas, bem como a distribuição dos operadores. 
Figura 7 - Distribuição dos Recursos nas Operações Estado Futuro

\begin{tabular}{ccc}
\hline Máquina & Operação & Operador \\
\hline 1 & Tornear Perfil & $\mathrm{A}$ \\
2 & Tornear Perfil & $\mathrm{A}$ \\
3 & Tornear Encaixe de Porca & $\mathrm{A}$ \\
4 & Brochar Entalhado & $\mathrm{B}$ \\
7 & Balancear & $\mathrm{B}$ \\
5 & Fresar & $\mathrm{C}$ \\
6 & Furar e Rosquear & $\mathrm{C}$ \\
8 & Olear e Empacotar & $\mathrm{C}$ \\
\hline
\end{tabular}

Com a nova proposta de alocação dos recursos, construiu-se o Mapeamento do Fluxo de Valor do Estado Futuro - MFV. No MFV futuro, delimitaram-se os estoques intermediários, a fim de nivelar a carga de trabalho entre as operações, e introduziu-se o conceito de produção puxada, para assim, reduzir os estoques intermediários.

O Operador A manteve as mesmas atividades. Entretanto, o operador B, responsável apenas pela máquina 4 , passou a exercer também as atividades da máquina 7 . O Operador $\mathrm{C}$ teve as atividades das operações finais (olear e empacotar) acrescidas às suas atividades. Desta forma, foi estruturado o novo trabalho combinado e novo gráfico Yamazumi. Os resultados de utilização obtidos no novo balanceamento determinístico estão descritos na Tabela 4.

Tabela 4 - Dados obtidos no Gráfico Yamazumi Estado Futuro

\begin{tabular}{cccccc}
\hline Operador & Utilização & Agrega Valor & Não Agrega Valor & Caminhada & Pausa \\
\hline A & $94 \%$ & 58 segundos & 52 segundos & 16 segundos & 41 segundos \\
B & $80 \%$ & 41 segundos & 24 segundos & 13 segundos & 65 segundos \\
C & $75 \%$ & 44 segundos & 39 segundos & 16 segundos & 44 segundos \\
\multicolumn{2}{c}{ Total } & 143 segundos & 115 segundos & 45 segundos & 150 segundos \\
\hline
\end{tabular}

Fonte: Elaborada pela autora

Com as modificações propostas a partir da simulação computacional foi possível identificar um aumento de $32 \%$ na utilização do operador C. Otimizou-se a necessidade de recursos humanos para produção, uma vez que foram agregadas atividades para o operador B, obtendo-se uma melhoria de 76,25\% em sua utilização.

Calculou-se novamente o percentual de ociosidade $(34,72 \%)$, para verificação de defasagem no balanceamento. Obteve-se uma melhoria de $28,82 \%$ no percentual de ociosidade da célula de manufatura. A partir do novo balanceamento, reduziu-se para 2,94 dias o lead time para produção de uma peça, visto que a carga de trabalho balanceada reduziu o estoque em processo. Assim, obteve-se uma redução de 77,62\% no lead time para produção.

A partir destes resultados, iniciou-se um novo ciclo de integração de técnicas de balanceamento determinística e estocástica, a fim de otimizar os recursos utilizados.

\section{Conclusões}

A partir da estruturação de uma sistemática integrada de técnica determinística e estocástica para balanceamento de célula de manufatura foi possível avaliar uma proposta de balanceamento para célula de manufatura em uma empresa. 
Utilizando a ferramenta Yamazumi, a qual retrata as atividades do trabalho combinado dos operadores por posto de trabalho, foi possível obter uma estimativa da utilização dos operadores. Após estruturar o Yamazumi, utilizou-se a ferramenta de simulação computacional, para demonstrar o real comportamento da célula de manufatura. E assim, foi possível avaliar a utilização dos operadores considerando o cenário de manufatura que apresentava paradas de máquina por espera de peças, movimentações, inspeções de qualidade, entre outros.

Desta forma, pode-se demonstrar que, utilizando de forma integrada a sistemática Yamazumi e a simulação computacional, é possível realizar o balanceamento dos recursos, e entender de forma sistêmica todo o processo produtivo e suas restrições. Utilizando isoladamente a sistemática Yamazumi limita-se a análise de utilização dos operadores baseada em dados determinísticos, o que não remete à realidade dos sistemas de manufatura.

A utilização desta sistemática permitiu a identificação de possibilidades de melhoria no balanceamento e possibilitou a estruturação de um novo gráfico Yamazumi, baseado nos resultados obtidos na simulação. A simulação computacional pode ser utilizada como ferramenta de apoio a técnicas estruturadas de balanceamento determinístico, permitindo análises das variabilidades no processo (máquinas, recursos, entidades, locais, entre outros).

O objetivo geral deste trabalho foi atendido, visto que foi proposta uma sistemática para balanceamento de célula de manufatura integrando abordagens determinística e estocástica. Foram analisadas as sistemáticas de balanceamento utilizadas. Simulou-se o balanceamento determinístico utilizando a simulação computacional. E, por fim, comparou-se os resultados obtidos nas abordagens determinística e estocástica.

Este trabalho deixa como contribuição a conclusão de que uma sistemática integrada de técnica de determinística com a simulação computacional permite avaliar de forma sistêmica a célula de manufatura, e assim, ter um melhor entendimento das variabilidades dos processos.

Neste trabalho não foi realizada a simulação computacional do estado futuro proposto. A simulação do estado futuro inicia um novo ciclo da sistemática proposta. Sugerese para os trabalhos futuros, a utilização da sistemática por mais ciclos objetivando a confirmação de resultados futuros e a melhoria contínua do processo de balanceamento.

\section{Referências}

ANGRA, S.; SEHGAL, R.; NOORI, Z. S. Cellular manufacturing: A time-based analysis to the layout problem. International Journal Production Economics. n. 112, p. $427-438,2007$.

ANTUNES JR., J.: Em direção a uma teoria geral do processo na administração da produção: uma discussão sobre a possibilidade de unificação da teoria das restrições e a teoria que sustenta a construção dos sistemas de produção com estoque zero. Tese de doutorado em Administração de Empresas, Programa de Pós-Graduação em Administração da UFRGS, Porto Alegre, RS, 1998.

ALVAREZ, R. R.; ANTUNES JR, J. Takt-Time: Conceitos e Contextualização dentro do Sistema Toyota de Produção. Revista Gestão \& Produção. V.8, n. 1, p. 118, abr. 2001.

ASKIN, R. G.; ZHOU, M. A parallel station heuristic for the mixed model production line balancing problem. International Journal of Production Research, London (Inglaterra), v. 35, n. 11, p. 3095-3105, 1997.

BANKS, J. Introduction to simulation. Proceedings of the Winter Simulation Conference. Atlanta, 2000. 
BARNES, R.M. Estudo de Movimentos e de tempos: projeto e medida do trabalho. São Paulo: Ed. Blucher, 1977. 634p.

BARROSO, U. I. B.; TUBINO, D. F. O layout celular na indústria moveleira de estofados. XXIV Encontro Nacional de Engenharia de Produção, 2004, Florianópolis, SC, nov. 2004.

BLACK, J. T. O projeto da Fábrica com Futuro. Porto Alegre: Bookman, 2001.

CARSON, J; Introduction to modeling and simulation. Winter Simulation Conference, 2004.

CHIROLI, D. G. G.; NUNES, P. V.; LEAL, G. C. L. O uso da cronoanálise para implantação do plano mestre de produção em uma empresa avícola. XXX Encontro Nacional de Engenharia de Produção, São Carlos, SP, Brasil, 12 a 15 de Outubro de 2010.

CONCEIÇÃO, S. V. Otimização do Fluxo de Materiais através da Manufatura Celular. Revista Produção. v. 15, n. 2, p. 235-250, Maio/Ago. 2005.

GERHARDT, M. P.; FOGLIATTO, F. S. Balanceamento de linhas de montagem multi-modelos. XXIV Encontro Nacional de Engenharia de Produção, Florianópolis, SC, nov. 2004.

GIL, A. C. Como Elaborar Projetos de Pesquisa. 5a edição. São Paulo: Editora Atlas S.A., 2010.

GOGG, T. J.; MOTT, J. R. Improve quality \& productivity with simulation. 2. Ed. JMI Consulting Group, 1995.

GOMES, J. E. N.; OLIVEIRA, J. L. P.; ELIAS, S. J. B.; BARRETO, A. F.; ARAGÃO, R.L. Balanceamento de linha de montagem na indústria automotiva - um estudo de caso. XXVII Encontro Nacional de Engenharia de Produção, Rio de Janeiro, RJ, out.2008.

GUINATO, P. Produção e Competitividade: Aplicação e Inovações. Tradução: Adiel Almeida e Fernando Souza. Recife: UFPE, 2000

EREL, E.; GOKCEN, H. Shortest-route formulation of mixed-model assembly line balancing problem. European Journal of Operational Research, $\mathrm{n}^{\circ} 116$, p. 194204, 1999.

FARNES, V. C. F.; PEREIRA, N. A. Balanceamento de linha de montagem com o uso de heurística e simulação: estudo de caso na linha branca. XIII Simpósio de Engenharia de Produção. Bauru, SP, Brasil, 6 a 8 de Novembro de 2006.

FERNANDES, C. F. F.; FILHO, M. G.; CUTIGI, R. A.; GUIGUET, A. M.; O uso da programação inteira 0-1 para o balanceamento de linhas de montagem: modelagem, 
estudos de caso e avaliação. Revista Produção. v. 18, n. 2, p. 210-221, maio/ago. 2008

FERNANDES, F. C. F.;DALALIO, A. G. Balanceamento e rebalanceamento de linhas de montagem operadas por grupos de trabalho autogerenciados. Revista Gestão \& Produção. v.7, n.3, p.378-398, dez. 2000.

KHAN, A.; DAY, A. J. A Knowledge Based Design Methodology for manufacturing assembly lines. Computers \& Industrial Engineering, Los Angeles (EUA), v. 41, n. 4, p. 441-467, 2002.

LAW, A. M.; KELTON, W. D. Simulation Modeling and Analysis. $3^{\text {a }}$ ed. Boston: McGrawHill, 2000. 760p.

LEHMAN, M. On criteria for assigning models to assembly lines. International Journal of Production Research, London (Inglaterra), v. 7, n. 4, p. 269-285, 1969.

LIKER, J. K. O Modelo Toyota: 14 princípios de gestão do maior fabricante do mundo. Porto Alegre: Bookman, 2005. 316p.

LOBÃO, E. C.; PORTO, A;. J. V. Evolução das técnicas de simulação. Revista Produção. São Paulo, v. 9, n. 1, p. 13-21, jan./jun. 1999.

LU, M.; WONG, L.; Comparison of two simulation methodologies in modeling construction systems: Manufacturing-oriented PROMODEL vs. construction-oriented SDESA. Automation in Construction. n. 16, p. 86-95, 2005.

MARODIN, G.; SAURIN, T. A. Modelo de Avaliação de Arranjos Físicos sob a ótica da Manufatura Celular. Revista Gestão Industrial. v. 03, n. 03: p. 66-86, 2007

MASSOD, S. Line balancing and simulation of an automated production transfer line. Assembly Automation. 26,/1, p. 69 - 74, 2006.

MENDES, A. R.; RAMOS, A. L.; SIMARIA, A. S.; VILARINHO, P. M. Combining heuristic procedures and simulation models for balancing a PC camera assembly line. Computers \& Industrial Engineering. n. 49, p. 413-431, 2005.

MILTENBURG, J. U-shaped production lines: A review of theory and practice. International Journal Production Economics. n. 70, p. 201 - 214, 2001.

OHNO, T. O Sistema Toyota de Produção: além da produção em larga escala. Porto Alegre: Bookman, 149 p. 1997.

OLIVEIRA, F. U. N.; SILVA, I. B.; HELLENO, A. L. Metodologia MTM (Methods - Time Measurement) como estratégia competitiva para um balanceamento de linha de produção mais exuto. XXI Encontro Nacional de Engenharia de Produção, Belo Horizonte, MG, out. 2011. 
OLORUNNIWO, F.; UDO, G. The impact of management and employees on cellular manufacturing implementation. International Journal Production Economics. n. 76, p. $27-38,2002$.

PINHO, A. F.; LEAL, F.; MONTEVECHO, J. A. B.; MARINS, F. A. S; MAPA, S. M. S.; RIBEIRO, M. J. C. Aumento de Produtividade em uma Linha de Montagem de Chassis Automotivos Através da Simulação Computacional. XVI Encontro Nacional de Engenharia de Produção, Fortaleza, CE, out. 2006.

PRASAD, P. S. S.; ARAVINTHAN, G.. Development of Cellular Layout for a Pump Manufacturing Industry. The IUP Journal of Operations Management, vol.X, n.2, 2011.

ROTHER, M.; HARRIS, R. Criando fluxo contínuo: um guia de ação para gerentes, engenheiros e associados da produção. São Paulo: The Lean Enterprise Institute, 2002.

SHINGO, S. O Sistema Toyota de Produção: do ponto de vista da engenharia de produção. Porto Alegre: Bookman, 1996.

SILVA, L. M. F; PORTO, E. S. O balanceamento do fluxo produtivo à luz da TOC: caso prático no processo demontagem de calçados autoclavados. XXVIII Encontro Nacional de Engenharia de Produção, Rio de Janeiro, RJ, out.2008.

SILVA, J. M. A.; JUNIOR, M. V.; COPPINI, N. L.; BAPTISTA, E. A.; PILEGGI, G. C. F. Balanceamento de células flexiveis de manufatura pela otimização das condições operacionais e uso do software Arena. XXX Encontro Nacional de Engenharia de Produção, São Carlos, SP, Brasil, 12 a 15 de Outubro de 2010

SLACK, N.; CHAMBERS, S.; JOHNSTON, R. Administração da Produção. 2. ed. São Paulo: Atlas, 2006.

STEVENSON, W. J. Administração das operações de produção. 6. ed. Rio de Janeiro : LTC, 701 p., 2001.

TUBINO, D. F. Sistemas de Produção: a produtividade no chão-de-fábrica. Porto Alegre: Bookman, 1999. 134p.

WHITFIELD, K. Building better powertrains through lean approaches at Toyota. Automotive Design \& Production. n. 113, 5, p. 70 - 73, May, 2001. 